\title{
Curvilinear steel elements in load-bearing structures of high-rise building spatial frames
}

\author{
Alexander Ibragimov ${ }^{1, *}$, Alexander Danilov ${ }^{1}$ \\ ${ }^{1}$ Moscow State University of Civil Engineering, Yaroslavskoye shosse, 26, Moscow, 129337, Russia
}

\begin{abstract}
The application of curvilinear elements in load-bearing metal structures of high-rise buildings supposes ensuring of their bearing capacity and serviceability. There may exist a great variety of shapes and orientations of such structural elements. In particular, it may be various flat curves of an open or closed oval profile such as circular or parabolic arch or ellipse. The considered approach implies creating vast internal volumes without loss in the load-bearing capacity of the frame. The basic concept makes possible a wide variety of layout and design solutions. The presence of free internal spaces of large volume in "skyscraper" type buildings contributes to resolving a great number of problems, including those of communicative nature. The calculation results confirm the basic assumptions.
\end{abstract}

\section{Introduction}

The principal reasons for the steel application for high-rise buildings are:

- Steel frames are fast to erect. The construction is lightweight, particularly in comparison with traditional concrete construction.

- The elements of the framework are prefabricated. Factory conditions of manufacturing lead to established quality mounting procedures.

- The dryness of the form of construction results in less on-site activities. gain.

- The framework is not susceptible to drying-out effects or delays due to strength

- Steel frames have potential for adaptability inherent in their construction. Later modification involves relatively easy unbolting a connection; with concrete, such modifications would be expensive, and more extensive and disruptive.

- The use of steel makes possible the creation of relatively large, column-free internal spaces to divide if needed by partitions.

- With no external walls as loadbearing elements, it allows the development of large window areas incorporated in prefabricated cladding systems.

The article [1] discusses the motivation for using curvilinear steel elements (C-els in brief) in the buildings structures. In [2-3] the various aspects of load-carrying structures of low- and in [4-6] of high-rise buildings design are considered. The key issue is the volume reduction of labor-intensive routine operations requiring enhanced accuracy of fit and

*Corresponding author: igasu_alex@mail.ru 
special surfacing operations at the stage of erection.

This paper presents the results of the influence of C-elements on the behavior of steel frameworks in high-rise buildings analysis.

It shows that, when properly used, such elements are capable of providing the necessary rigidity of the carcass. The vast free spaces for various purposes within the building's volume, as well as wide through openings are possible.

Obviously, with such an approach, an infinite number of variants of constructive schemes are possible. Shapes and orientation of curves far from exhausting the variety of parameters that determine the structural form of the framework. The choice of a particular variant and its justification are the prerogative of architects and design engineers.

Here it presents a relatively simple and maybe rather clumsy from the architectural point of view constructive forms. Yet it allows performing a comparative analysis and this is the main purpose of its presentation. Just from these examples it follows that the formation of a constructive form of a similar type, enough adequate to ensuring the bearing capacity, is not a routine procedure and requires the comparative structural and numerical analysis of a number of design variants and, accordingly, constructive models [7].

Allowing for a large number in tall buildings of connection joints of vertical (columns) and horizontal (crossbars, beams) steel elements with different cross sections, it is quite natural to strive for maximum simplification of such connections. The simplest and most technologically feasible solution to the junction of the beam to the column is the socalled "simple connection", where the moment transmitted by one element to the other is negligible enough. Along with the economic aspect, it should be noted here that the sensitivity of the carcass to a different kind of skew due to foundation sediment, temperature effects and other factors.

Therefore, the functioning of the frame elements differentiation takes place. Columns and crossbars provide the work of the frame on the perception of vertical loads, and bracing systems practically not involved in the perception of vertical loads perceive and transmit to the foundations horizontal impacts [8].

For curvilinear elements this functionality separation does not go. They simultaneously participate in the work of the main load-bearing elements of the framework on the perception of both vertical and horizontal loads. This, on the one hand, complicates the work of the frame and, allowing for the variety of design options, significantly complicates the calculation and design of structures. On the other hand, this opens up new opportunities for the generating of constructive and, thus, architectural forms.

\section{Bearing structures analysis}

Consider a flat frame (in particular, with lattice rigidity diaphragms) scheme, in which the C-elements embed in a most natural way. A $36 \mathrm{~m}$ long building of $24 \mathrm{~m}$ depth, height $H=$ $120 \mathrm{~m}$ (30 floors of $4 \mathrm{~m}$ ) has a pitch of columns $6 \mathrm{~m}$ in both directions.

The averaged dead (D) vertical load on the crossbars (primary beams) of the flat bearing frame is assumed to be $60 \mathrm{kN} / \mathrm{m}$ according to $10 \mathrm{kN} / \mathrm{m}^{2}$ of design load on the slab. It includes here permanent like the reinforced concrete slab $(200 \mathrm{~mm})$ weight and, to simplify the model, all the long- and short-term (useful) variable loads.

The wind load (V) acts from left to right and, taking into account the dynamic (pulsation) component, is approximately assumed to be trapezoidal: $1.50 \mathrm{kN} / \mathrm{m}$ at ground level and $4.22 \mathrm{kN} / \mathrm{m}$ at a height of $120 \mathrm{~m}$ on the windward side (left) and 0.94 and 2.64 $\mathrm{kN} / \mathrm{m}$, respectively, on the opposite side (right). Load combinations [D] and [D $+\mathrm{V}]$ are considered.

The first case observes the effect of the curvilinear elements embedding as such into the frame system, as well as the cross-sections for these elements, on the behavior of the frame 
with rigid connections of the crossbars to columns. C-elements rigidly connect to columns and crossbars. The cross-section of columns is of paired I-beams 60SH2 with 90x10-angle lattice, cross-section of crossbars - 35SH2 according to STO ASCHM 20-93. Columns to foundations connections are fixed - rigid support.

The values of the maximum horizontal displacement of the middle node at the level of $120 \mathrm{~m}$ (frame top) and the stability factor for the first buckling mode are the comparison criteria. The stability factor $(k)$ is the ratio of the frame global buckling load level to a given one.

The one result of the several framework variants FEA in LIRA-SAPR program is that all the frame elements have sufficient load-bearing capacity. However, as for deformability and stability of the framework system as a whole object, the results of the analysis differ significantly (Table 1).

It is easy to see that the scheme $(a)$ does not satisfy the serviceability requirements, since the relative horizontal wind load deflections exceed the standard maximum value of $1 / 500$. Scheme $(b)$ with the smallest of the last three variants of the C-elements crosssection is quite acceptable. At the same time, the FEA analysis shows a number of the crossbars in the scheme (a) to be overloaded (within 10\%), unlike in the schemes (b) - (c). It is clear that the scheme (a) in case of crossbars to columns hinged connections (simple connections) is practically unworkable without the diagonal stiffness elements in the frame plane.

Table 1. First buckling modes and horizontal wind displacements for the high-rise building schemes under consideration with rigid beam to column joints.

\begin{tabular}{|l|c|c|c|c|}
\hline $\begin{array}{c}\text { Rigid column-beam } \\
\text { joint frames first } \\
\text { buckling modes }\end{array}$ &
\end{tabular}

The Table. 2 shows that in all four cases in order to ensure an acceptable rigidity the carcass requires a stiffening diaphragms. The single chord C-elements themselves also do not provide the required stiffness of the carcass. However, one may suppose the proper shape, cross-sections and arrangement of $\mathrm{C}$-elements to make it quite possible. For example, using more rigid two-chord $\mathrm{C}$-elements with a diagonal grating ( $\mathrm{C}$-trusses).

Table 2. Horizontal displacement in frames with hinged beams

\begin{tabular}{|l|c|c|c|c|}
\hline Scheme type & $a$ & $b$ & $c$ & $d$ \\
\hline Deflection $d x, \mathrm{~mm}$ & 40460 & 739 & 619 & 346 \\
\hline Relative, $d x / H$ & $1 / 3$ & $1 / 162$ & $1 / 194$ & $1 / 347$ \\
\hline
\end{tabular}

The stiffness diaphragms being inserted (vertical bracing of CHS $203 \times 10$ cross-section) the picture changes drastically (Table 3). 
Note that in schemes $(e)-(h)$ all horizontal elements (crossbars) have simple (no bending moments in joints) connections with columns and arches. The arch to column and column to base connections are rigid (fixed). The embedding of $\mathrm{C}$-elements into the frame structure obviously several times increases the stiffness and stability of the frame (table 3) turning the "sway-sensitive" structure into "non-sway" one without any other bracing system based traditionally on a great number of diagonal elements. Scheme types (e) and (f) show the bracing system influence on the frame "sway-sensitivity".

Table 3. First buckling modes and horizontal wind displacements for the high-rise building schemes under consideration with simple joints.

\begin{tabular}{|c|c|c|c|c|}
\hline $\begin{array}{l}\text { Simple column- } \\
\text { beam joint frames } \\
\text { first buckling } \\
\text { modes }\end{array}$ & 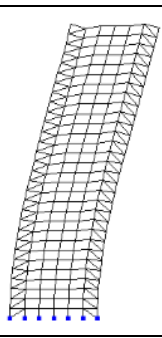 & 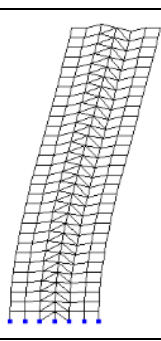 & 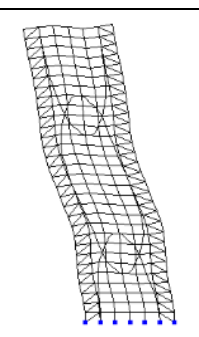 & $\begin{array}{r}+1 \\
\square+1 \\
\square+1\end{array}$ \\
\hline Scheme type & $e$ & $f$ & $g$ & $h$ \\
\hline Details & No C-els & No C-els & $\begin{array}{c}\text { C-els of paired } \\
30 \mathrm{SH} 2\end{array}$ & $\begin{array}{c}\text { C-els of paired } \\
50 \mathrm{SH} 3\end{array}$ \\
\hline Deflection $d x, \mathrm{~mm}$ & 504 & 266 & 106 & 80 \\
\hline Relative, $d x / H$ & $1 / 238$ & $1 / 451$ & $1 / 1132$ & $1 / 1500$ \\
\hline Stability factor $k$ & 2.22 & 4.16 & 8.77 & 10.11 \\
\hline
\end{tabular}

It makes it allowable to weaken the framework by introducing some openings, say, as shown in Table. 4.

Table 4. First buckling forms and horizontal wind displacements for the high-rise building schemes under consideration with simple joints and openings.

\begin{tabular}{|c|c|c|c|c|}
\hline $\begin{array}{l}\text { Simple column- } \\
\text { beam joint frames } \\
\text { first buckling modes }\end{array}$ & 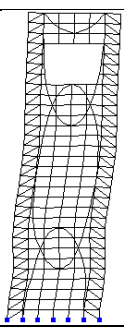 & \begin{tabular}{|l|l|} 
\\
\\
\end{tabular} & 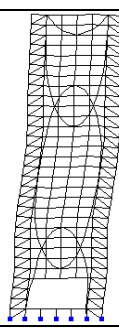 & 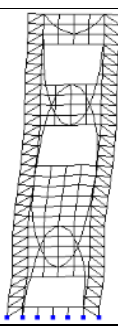 \\
\hline Scheme type & $i$ & $j$ & $k$ & $l$ \\
\hline Details: openings & Top & Middle & Bottom & 3-level \\
\hline Deflection $d x, \mathrm{~mm}$ & 77 & 77 & 77 & 84 \\
\hline Relative, $d x / H$ & $1 / 1558$ & $1 / 1558$ & $1 / 1558$ & $1 / 1429$ \\
\hline Stability factor $k$ & 11.24 & 11.23 & 10.12 & 11.98 \\
\hline
\end{tabular}

In the schemes $(i)-(l)$ top C-elements are of paired $35 \mathrm{SH} 2$ cross-section and all the lower of paired 50SH2. The columns, beams and diagonals are of the same cross-sections as before: paired $60 \mathrm{SH} 2$, single $35 \mathrm{SH} 2$ and $\mathrm{CHS} 203 \times 10$ correspondently. The FEA analysis showed that in $k$ and $l$ cases the bottom $\mathrm{C}$-elements and bottom level columns and diagonals should be somewhat enhanced. The vertical deflections on the top of frame and in the openings still meet the regulatory requirements.

The table 4 shows the significant reserve of bearing capacity of frames with openings. At least two point one should outline here: the required cross-sections of diagonals and all 
bearing elements but beams will decrease with increasing elevations; the presence of openings may also decrease vertical loads (see the stability factor values) and frontal wind action (reduction of impact area).

The next sample is a spatial $3 \mathrm{~d}$-model of a 33-storey building $(\mathrm{H}=132 \mathrm{~m})$ in the Table 5. Here the first several floors columns cross section is increased (70SH3). The reinforced concrete slabs $200 \mathrm{~mm}$ thick form the horizontal diaphragms at each floor level.

Table 5. 33-flor high-rise building $132 \mathrm{~m}$ height with C-beams and openings.

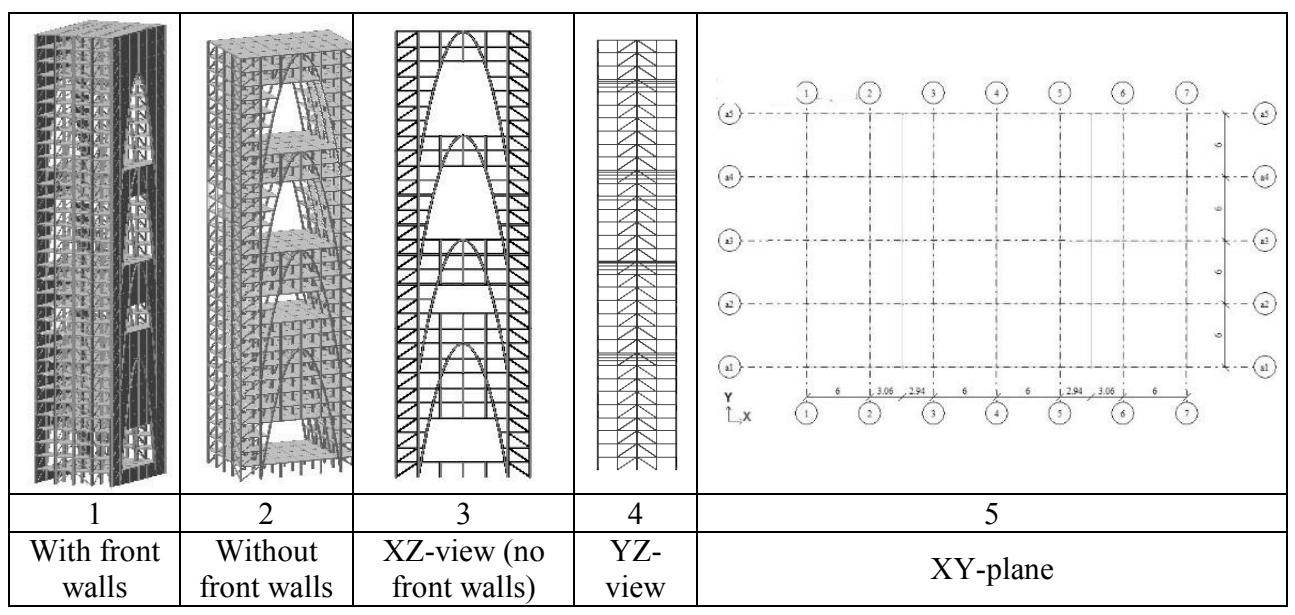

To account for the openings in a most simple way, when setting the front and backside wind load, the flat finite elements with small shear stiffness model the enclosing structure on the front and backsides of the building design model. The vertical action is a uniformly distributed load on the floor flat finite elements of $10 \mathrm{kN} / \mathrm{m}^{2}$ intensity. Lateral (X direction) and front ( $\mathrm{Y}$ direction) wind loads have the same intensity as before. The lateral wind load applies directly to the columns (see previous models). The column-beam and arch-beam joints - simple (hinged). The reinforced concrete slab of floors connects to columns rigidly - joints with additional plated elements.

Applied loads:

1. D - Dead load

2. WX - Wind along X-axis

3. WY - Wind along Y-axis

4. SX - Seismic (5b) along X-axis

5. SY - Seismic (5b) along Y-axis

Table 6. Load combinations considered and FEA results

\begin{tabular}{|c|c|c|c|c|c|c|}
\hline \multirow{2}{*}{\multicolumn{2}{|c|}{ Combinations: }} & \multicolumn{3}{|c|}{ Deflections, $\mathrm{mm}$} & Period, $\mathrm{s}$ & Stability factor $k$ \\
\hline & & $\mathrm{X}$ & $\mathrm{Y}$ & $\mathrm{Z}$ & $1^{\text {st }}$ mode & \\
\hline 1 & $\mathrm{D}$ & 0 & 0 & -95 & \multirow{7}{*}{4.5} & 4.69 \\
\hline 2 & $\mathrm{D}+\mathrm{WX}$ & 31 & 0 & -95 & & 4.24 \\
\hline 3 & $\mathrm{D}+\mathrm{WY}$ & 0 & 108 & -95 & & 4.21 \\
\hline 4 & $\mathrm{D}+\mathrm{SX}$ & 0 & 231 & -95 & & \multirow[t]{4}{*}{ 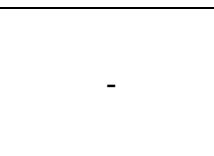 } \\
\hline 5 & $\mathrm{D}+\mathrm{SY}$ & 78 & 2 & -95 & & \\
\hline 6 & $0.9 \mathrm{D}+0.5 \mathrm{WX}+\mathrm{SX}$ & 15 & 231 & -86 & & \\
\hline 7 & $0.9 \mathrm{D}+0.5 \mathrm{WY}+\mathrm{SY}$ & 78 & 55 & -86 & & \\
\hline
\end{tabular}

The table 5 shows:

- deflection values lie in the admissible interval: $120000 / 500=240$ (note that deflection values are obtained for design load values) 
- there is sufficient margin of stability

- the first mode oscillations period may ensure the comfort of staying in the premises of the upper floors

Along with the task of ensuring the strength and stability of the bearing elements of the steel frame with increasing the height of the building and, respectively, the ratio of its vertical and horizontal dimensions, the stiffness and the stability margin of the carcass as an integral structural element become increasingly dominant factors. It extends into the rod or shell and, at some point, the provision of the load-bearing capacity of the frame elements can no longer provide the load-bearing capacity of the structural system as a whole. That is, the constructive system becomes a new quality and the effectiveness of the determining the framework stiffness bracing system acquires a special significance. All kinds of "stress concentrators" also adversely affect the behavior of the constructive system and local reinforcement is far from always save the situation.

High-rise building of $204 \mathrm{~m}$ height (34 floors of $6 \mathrm{~m}$ or 68 of $3 \mathrm{~m}, 60 \times 60 \mathrm{~m}$ plan) with arched openings ([1]) is an example. One can easily design necessary element crosssections to provide them strength and buckling resistance, minimize vertical and even horizontal deflections to meet the rules. However, in this frame the four rigid towers in the corners of the building need some additional bracing system to unite them into overall spatial structure. It is interesting to obtain in result of numerical analysis that the most problematic segments are not the ones with openings where the arches serve as bracing but the middle ones between the openings.

Table 7. High-rise building with simply supported beams and openings $(48 \times 24 \mathrm{~h} \mathrm{~m})$

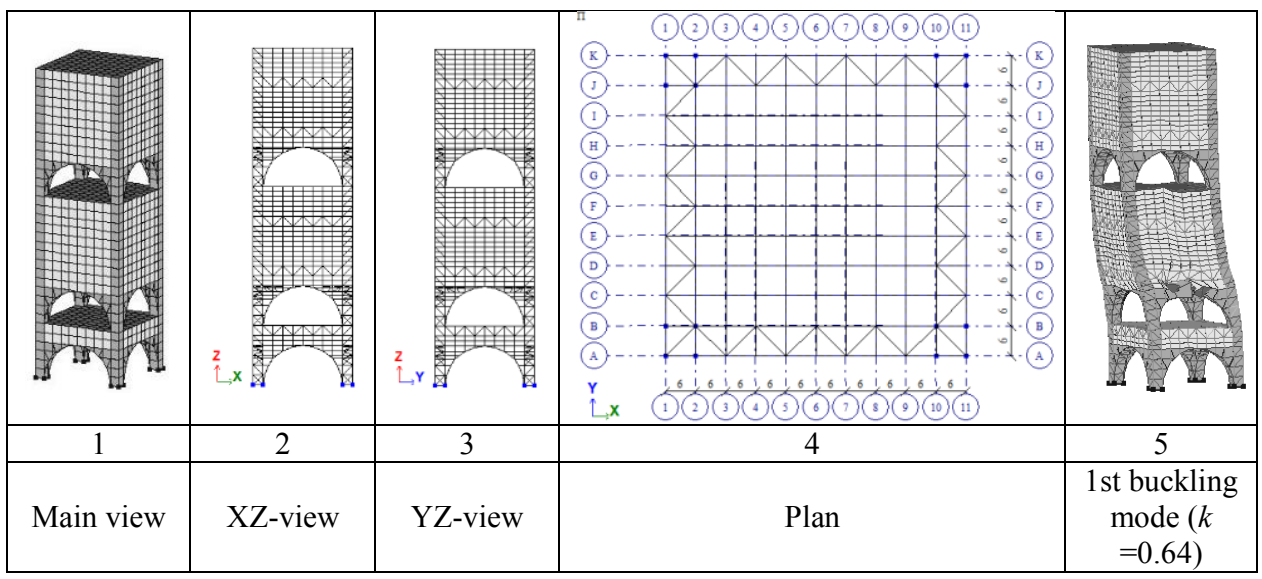

Introducing the considered earlier C-elements into the structure in a proper way one may possibly ensure the stability of the structure as a whole. The tables 3-5 give some examples. Various factors such as the maybe really the most critical ones like ground conditions may dictate the column grid. Long spans may be required to bridge obstructions beneath or over the ground: underground railways or archaeological remains 6 buried services, etc. Generally, a widely spaced column grid is desirable since it reduces the number of foundations and increases the simplicity of construction in the ground. A steelframed building is about $60 \%$ of the weight of a comparable reinforced concrete building resulting in smaller foundations with a consequent reduction on costs

\section{Conclusions}

The presented analysis results show: 
1. It is possible to use C-elements in high-rise building steel frames to ensure the robustness and buckling resistance of the structure as a whole system

2. The application of such constructive solutions makes it possible to form large-span openings and vast free internal spaces

3. This kind of applications especially needs thorough numerical analysis of structure behavior in various design situations

4. The variety of shapes and combinations of C-elements enables generating various architectural configurations

\section{References}

1. A. Tusnin, Industrial and Civil Engineering, 11, 18-22 (2017)

2. O. Tusnina, Industrial and Civil Engineering, 11, 23-27 (2017)

3. M.F. Randolph, C.P. Wroth Analysis of deformation of vertically loaded piles. Journal of the Geotechnical Engineering Division, 1978, vol. 104, no. 12, pp. 1465-1488.

4. A. Aminmansour, K. Moon, Journal of Architectural Engineering, 16 (2), 47-53 (2010)

5. W. Schueller, High-Rise Building Structures, Wiley, p. 272 (1977)

6. V. Faghihi, K.F. Reinschmidt, J.H. Kang, Expert Systems with Applications, 16, 7565-7578 (2014)

7. O. Kalinina, O. Valebnikova, Advances in Intelligent Systems and Computing, $\quad 692,1315-$ 1322 (2018) DOi - 10.1007/978-3-319-70987-1_139

8. I.V. Ilin, A. Lepekhin, A.I. Levina, O.Yu. Iliashenko, Advances in Intelligent Systems and Computing, 692, 1306-1314 (2018) DOi -10.1007/978-3-319-70987-1_138 